\title{
Machinability Effect During Milling on Different Composition of JFRP using Uncoated Carbide Cutting Tool
}

\author{
Mir Akmam Noor Rashid ${ }^{1}$, Zakaria Mohd Zain ${ }^{1}$, \\ Wazed Ibne Noor ${ }^{1}$ \\ ${ }^{*}$ Department of Mechatronics Engineering, International \\ Islamic University Malaysia, 53100, Gombak, \\ Selangor, Malaysia
}

\author{
Momin Mullah ${ }^{2}$ \\ ${ }^{2}$ Department of Electrical \&Computer Engineering, \\ International Islamic University Malaysia, 53100, \\ Gombak, Selangor, Malaysia
}

\begin{abstract}
Nowadays, jute fiber reinforcement polymer (JFRP) is used as a cost-effective, eco-friendly and obtainable material. It can be widely used in aircraft, marine, automotive, domestic upholstery approaches due to its various properties. During machining of JFRP, some problem arises in the time of assembly stage. Abrasive nature of jute fiber also effects on tool wear on the carbide cutting tools throughout the JFRP machining. For this reason, the life of the cutting tool becomes shorter and damages the surface quality. In this research, different compositions of the JFRP panel were fabricated and tool wear and delamination were measured after the $\mathrm{CNC}$ milling process. A preliminary experiment was conducted following the range of spindle speed from $1500 \mathrm{rev} / \mathrm{min}$ to $3500 \mathrm{rev} / \mathrm{min}$ and feed rate ranging from $150 \mathrm{~mm} / \mathrm{min}$ to $350 \mathrm{~mm} / \mathrm{min}$. Results revealed that tool wear is higher at 70/30 comparing to 60/40 JFRP panel and delamination is lower in $60 / 40$ panel comparing to $70 / 30$ panel. The selected 60/40 jute composite was machined in different feed rate, spindle speed, and depth of cut according to the design of experiment (DOE) table. It was found that tool wear is higher in higher spindle speed $(6328.43 \mathrm{rev} / \mathrm{min})$, feed rate $(391.42$ $\mathrm{mm} / \mathrm{min})$ and depth of cut $(2.21 \mathrm{~mm})$. Highest tool life was achieved at the lowest depth of cut $(0.79 \mathrm{~mm})$.
\end{abstract}

Keywords - JFRP; tool wear; tool life; delamination; solid carbide cutting tool omponent; formatting; style; styling;

\section{INTRODUCTION}

The importance of JFRP composite has quickly expanded in the fields of various application such as aviation, automotive, marine, and domestic appliances [1]. Fiber-reinforced polymer (FRP) has a particular specific quality, high modulus of strength, great production rate, good dimensional perfection. The mix of two different properties makes a stronger bond and rarely found in other compounds [2]. FRP composites are usually fabricated through hands lay-up technique, winding, extrusion, vacuums bagging, and molding [3]. However, a certain machining process is needed to get a close design, fittings, and tolerances. Machining processes are known as milling, drilling, slotting, turning, etc. FRP composites are the formation of two different properties in a one compound to increase the thermal and mechanical properties [4]. Jute fiber and epoxy resin are two different components in where reinforcement is jute fiber and epoxy resin is the polymer that plays an important role to form bonding with the fiber. JFRP composites are recently used as complex inter-connections between the matrix and reinforcement. The machining of
JFRP influences the materials and creating different types of problems. During machining fiber breakage, lattice splitting, fiber pull out generate and make difficulties in machining [5]. JFRP is a great degree of grating while machining and influence the execution of cutting devices with surface quality. Accordingly, the cutting tool and cutting conditions are necessary for the machining of composite materials. However, the demand for JFRP is increasing but the limited research is done to solve the machining problem at an optimum level. Some researchers focused on the machining f FRP composites in comparison to increase productivity comparing to traditional machining. Palanikumar et al. [6] focused on the machining of glass fiber composite machining. Until now, no research has been conducted to find out the machining performance on the JFRP panel. Actually, machining of JFRP in a different composition is quite hard due to discontinuity, anisotropic nature and different percentages of reinforcement and matrix material.

The research on different compositions of JFRP panel machining has become one of the major aspects to find out the suitable composite panel for machining which will give less effect on tool wear and delamination. In this study, machining on the JFRP panel has been focused to find out machining outcomes.

\section{MATERIAL AND METHODS}

The experimental process was conducted on different compositions of the JFRP panel by using the CNC machine. The fabrication was done using a hands lay-up technique. The first composite panel was made in $60 \%$ reinforcement and $40 \%$ matrix material which consists of 5 alternatives layers of jute fabric. The panel dimension was $200 \mathrm{~mm} \times 200 \mathrm{~mm} \times 5$ $\mathrm{mm}$. Another panel $70 / 30$ was fabricated by $70 \%$ reinforcement and $30 \%$ matrix material with the same dimension. Fig. 1 shows the illustration of the JFRP panel. An uncoated carbide-cutting tool with a diameter of $8.0 \mathrm{~mm}$, an overall length of $60 \mathrm{~mm}$, helix angle 300 with two flutes were used. Fig. 2 and Table 1 show the cutting tool and geometrical properties of the solid carbide tool respectively. Chemical and physical properties are demonstrated in Table 2 and Table 3. A CNC machine of $7.5 \mathrm{~kW}$ spindle power and a maximum spindle speed of $12000 \mathrm{rpm}$ was used. The tool wear of the cutting tool and Delamination were measured by using Nikon Measuring Microscope MM-400. After 200 mm 
distance traveling, the tool wear and delamination were recorded. Fig. 3 shows the machining set up of the JFRP panel. The machining set up is known as the clamping method. The panel was screwed on an aluminum supported tool. Fig. 4 shows the illustration of delamination measurement. Table 4 represents the general information of the JFRP panel. The selected composite was machined following DOE Table 5.

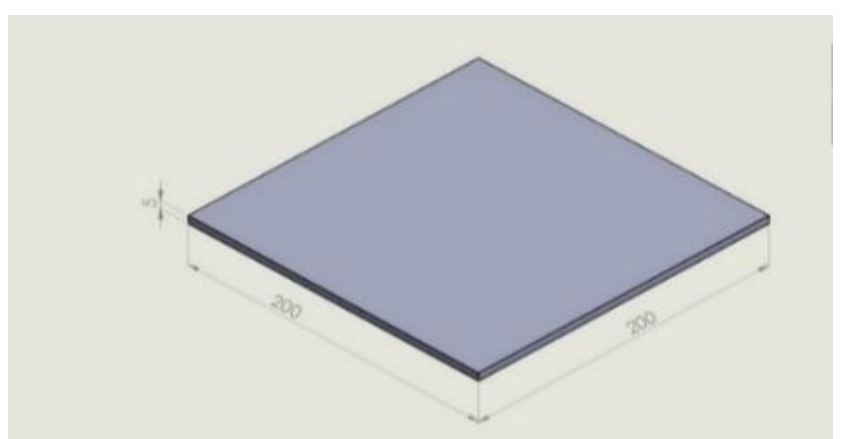

Fig 1. Illustration of JFRP panel

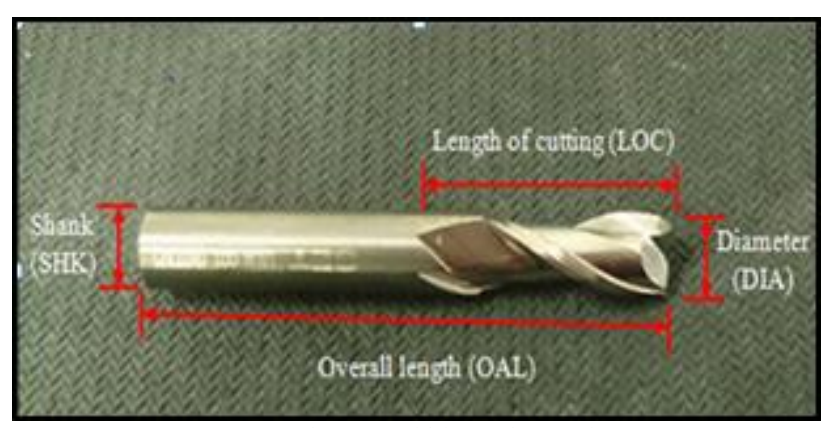

Fig 2. Carbide cutting tool

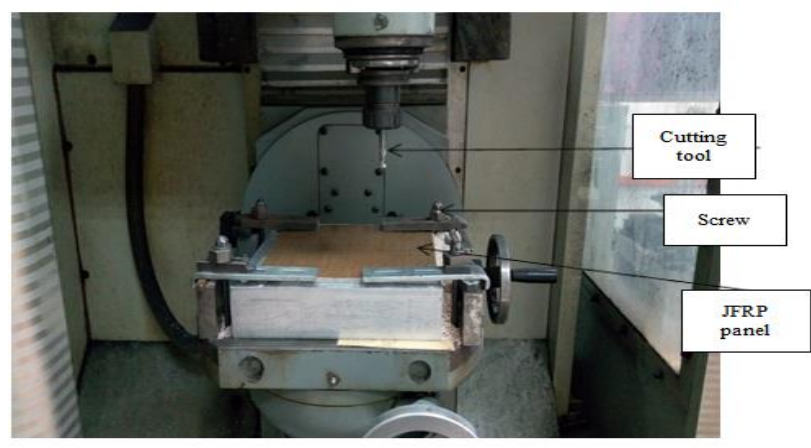

Fig 3. Machining set up

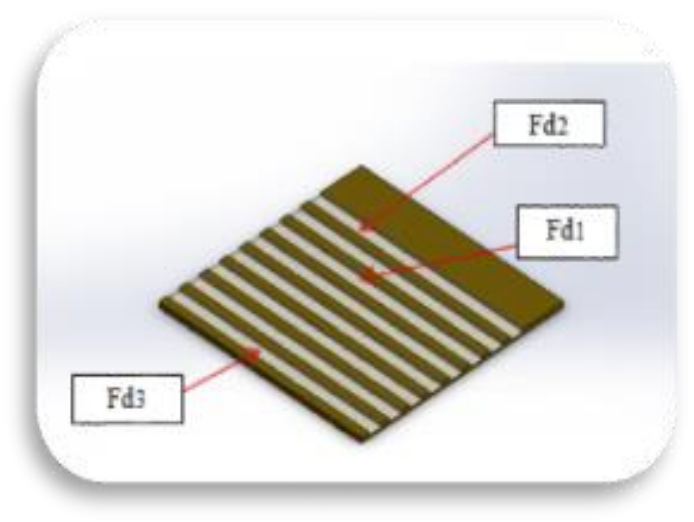

Fig 4. Delamination measurement
Table 1. Geometry of uncoated carbide cutting tool

\begin{tabular}{|llll|}
\hline DIA $(\mathbf{m m})$ & SHK $(\mathbf{m m})$ & OAL $(\mathbf{m m})$ & LOC $(\mathbf{m m})$ \\
\hline 8.0 & 8.0 & 60.0 & 20.0 \\
\hline
\end{tabular}

Table 2. Chemical composition of uncoated carbide cutting tool

\begin{tabular}{|c|c|}
\hline Element & Weight \% \\
\hline Tungsten Carbide, WC & $88.4-90.0$ \\
\hline Cobalt, Co & $9.5-10.5$ \\
\hline $\mathrm{VC}+\mathrm{Cr} 3 \mathrm{C} 2$ & $0.5-1.1$ \\
\hline
\end{tabular}

Table 3. Physical properties of uncoated carbide cutting tool

\begin{tabular}{|ll|}
\hline Density, $\mathbf{g} / \mathbf{c m 3}$ & Hardness, HRA \\
\hline $14.35 \pm 0.1$ & $9.18 \pm 0.5$ \\
\hline
\end{tabular}

Table 4. General information of JFRP panel

\begin{tabular}{|ll|}
\hline Panel & Property \\
\hline Resin type & Modified epoxy. Hexply @ 914 \\
Tg resin & $190^{\circ}$ \\
Yarn type & Tossa grade 1 \\
Fabric type & Woven \\
\hline
\end{tabular}

Table 5. Experimental Design

\begin{tabular}{|llll|}
\hline Run & $\begin{array}{l}\text { Spindle speed } \\
(\text { rev/min) }\end{array}$ & $\begin{array}{l}\text { Feed Rate } \\
(\mathrm{mm} / \mathrm{min})\end{array}$ & $\begin{array}{l}\text { Depth of cut } \\
(\mathrm{mm})\end{array}$ \\
\hline 1 & 3500.00 & 250.00 & 1.50 \\
2 & 6328.43 & 250.00 & 1.50 \\
3 & 3500.00 & 250.00 & 1.50 \\
4 & 3500.00 & 250.00 & 1.50 \\
5 & 3500.00 & 391.42 & 1.50 \\
6 & 3500.00 & 250.00 & 0.79 \\
7 & 5500.00 & 150.00 & 2.00 \\
8 & 3500.00 & 250.00 & 1.50 \\
9 & 3500.00 & 250.00 & 2.21 \\
10 & 3500.00 & 108.58 & 1.50 \\
11 & 1500.00 & 350.00 & 2.00 \\
12 & 1500.00 & 150.00 & 1.00 \\
13 & 3500.00 & 250.00 & 1.50 \\
14 & 5500.00 & 350.00 & 1.00 \\
15 & 671.57 & 250.00 & 1.50 \\
\hline
\end{tabular}

\section{RESULTS AND DISCUSSION}

\section{A. Tool Wear Analysis}

Tool wear is very important aspect that should to examined during machining. It can be seen that figure 5 (a) and (b) shows the effect of spindle speed and feed rate on the cutting tool. Figure 5 (a) shows that the different spindle speed 1500 $\mathrm{rev} / \mathrm{min}$ and $3500 \mathrm{rev}$ with a constant feed rate $150 \mathrm{~mm} / \mathrm{min}$, depth of cut $1 \mathrm{~mm}$. Here, the JFRP panel $60 / 40$ can be observed that at $3500 \mathrm{rev} / \mathrm{min}$ spindle speed tool wear $0.041 \mathrm{~mm}$ and $1500 \mathrm{rev} / \mathrm{min}$ gives $0.036 \mathrm{~mm}$. On the other hand, 70/30 JFRP panel shows that whenever spindle speed $3500 \mathrm{rev} / \mathrm{min}$ then the tool wear is $0.046 \mathrm{~mm}$ and the spindle speed is $1500 \mathrm{rev} / \mathrm{min}$ then the tool wear $0.033 \mathrm{~mm}$. It was found that due to the increase of spindle speed the tool wear increase also. The comparison study between these two composites. It was observed that $60 / 40$ composite panel tool life is better than 70/30 composite panel. Figure 5 (b) shows the feed rate effect on tool life in between two composite panel. It can be seen that the feed rate is increasing tool wear 
is increasing also. Many studies reported that feed rate effects on tool life significantly, due to the friction between the cutting tool and workpiece. The matrix removal is higher in the case of a higher feed rate. The feed rate was $150 \mathrm{~mm} / \mathrm{min}$ and $350 \mathrm{~mm} / \mathrm{min}$ with a constant spindle speed $3500 \mathrm{rev} / \mathrm{min}$ and depth of cut $1.0 \mathrm{~mm}$. The $60 / 40$ composite panel gives the tool wear $0.036 \mathrm{~mm}$ and $0.048 \mathrm{~mm}$ whenever the feed rate was $150 \mathrm{~mm} / \mathrm{min}$ and $350 \mathrm{~mm} / \mathrm{min}$. Another panel 70/30 shows that the tool wear $0.046 \mathrm{~mm}$ and $0.056 \mathrm{~mm}$ within the same feed rate like $150 \mathrm{~mm} / \mathrm{min}$ and $350 \mathrm{~mm} / \mathrm{min}$. To do compare, it can be seen that $60 / 40$ panel shows the better tool life compared to $70 / 30$ panel. It would be happened due to the less matrix percentage in 70/30 panel.

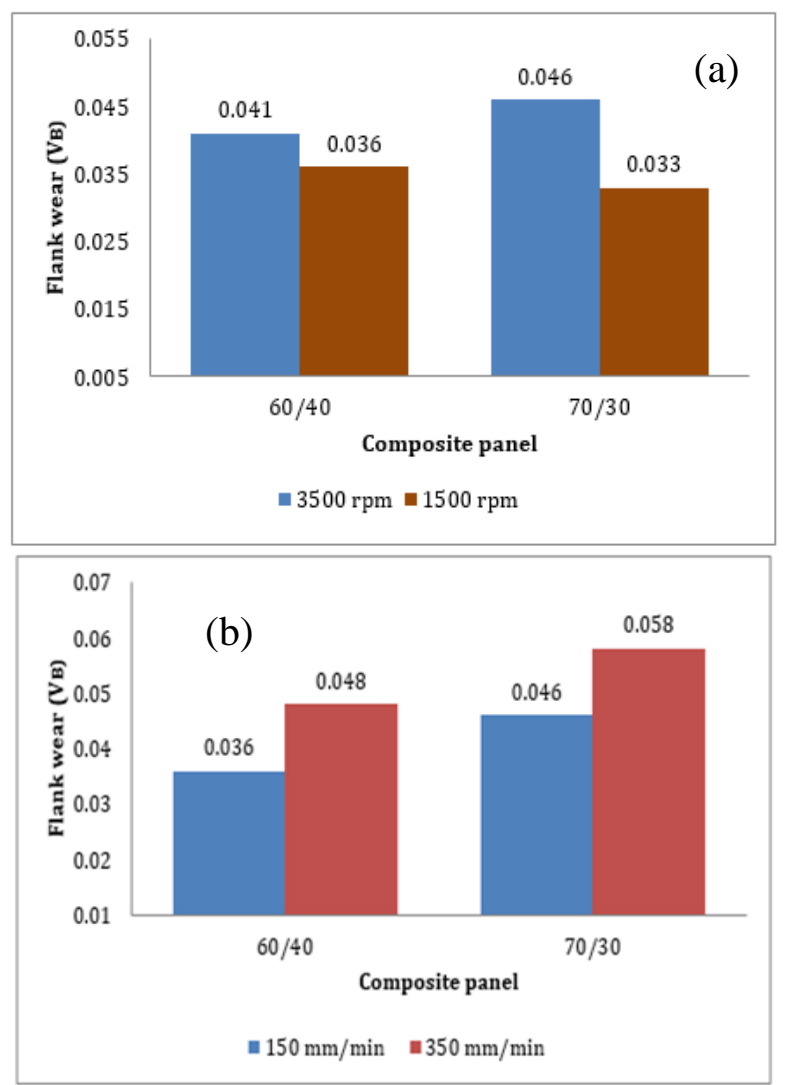

Figure 5 (a) Different spindle speed ( $3500 \mathrm{rpm} \& 1500 \mathrm{rpm}$ ) effect on Tool wear; (b) different feed rate $(350 \mathrm{~mm} / \mathrm{min}$ and $150 \mathrm{~mm} / \mathrm{min}$ ) effect on tool wear

\section{B. Delamination Analysis}

Delamination is one of the most important factors for the rejection of the industrially made components which draw serious attention to the engineers for machining JFRP. The delamination factor was measured for these two composite panels in different spindle speeds like $1500 \mathrm{rev} / \mathrm{min}$ and 3500 rev/min within constant feed rate $150 \mathrm{~mm} / \mathrm{min}$ and depth of cut $1 \mathrm{~mm}$. Figure 7 shows that, For $70 / 30$ panel, it was found that $1500 \mathrm{rev} / \mathrm{min}$ and $3500 \mathrm{rev} / \mathrm{min}$ spindle speed gives delamination $1.34 \mathrm{~mm}$ and $1.02 \mathrm{~mm}$. Similarly, for $60 / 40$ panel the same spindle speed gives $1.23 \mathrm{~mm}$ and $0.86 \mathrm{~mm}$ delamination. Delamination in $60 / 40$ is less than $70 / 30$ panel. Now the delamination measured on different feed rates like $150 \mathrm{~mm} / \mathrm{min}$ and $350 \mathrm{~mm} / \mathrm{min}$ with a constant spindle speed $3500 \mathrm{rev} / \mathrm{min}$ and depth of cut $1 \mathrm{~mm}$. Figure 8 shows that feed rate $350 \mathrm{~mm} / \mathrm{min}$ effect for $70 / 30$ and $60 / 40$ panel delamination was $1.31 \mathrm{~mm}$ and $1.22 \mathrm{~mm}$. For, $150 \mathrm{~mm} / \mathrm{min}$ feed rate shows the delamination was $1.11 \mathrm{~mm}$ and $1.02 \mathrm{~mm}$ for $70 / 30$ and $60 / 40$ panel. It was found that $60 / 40$ panel gives the lowest delamination comparing to $70 / 30$ composite panel.

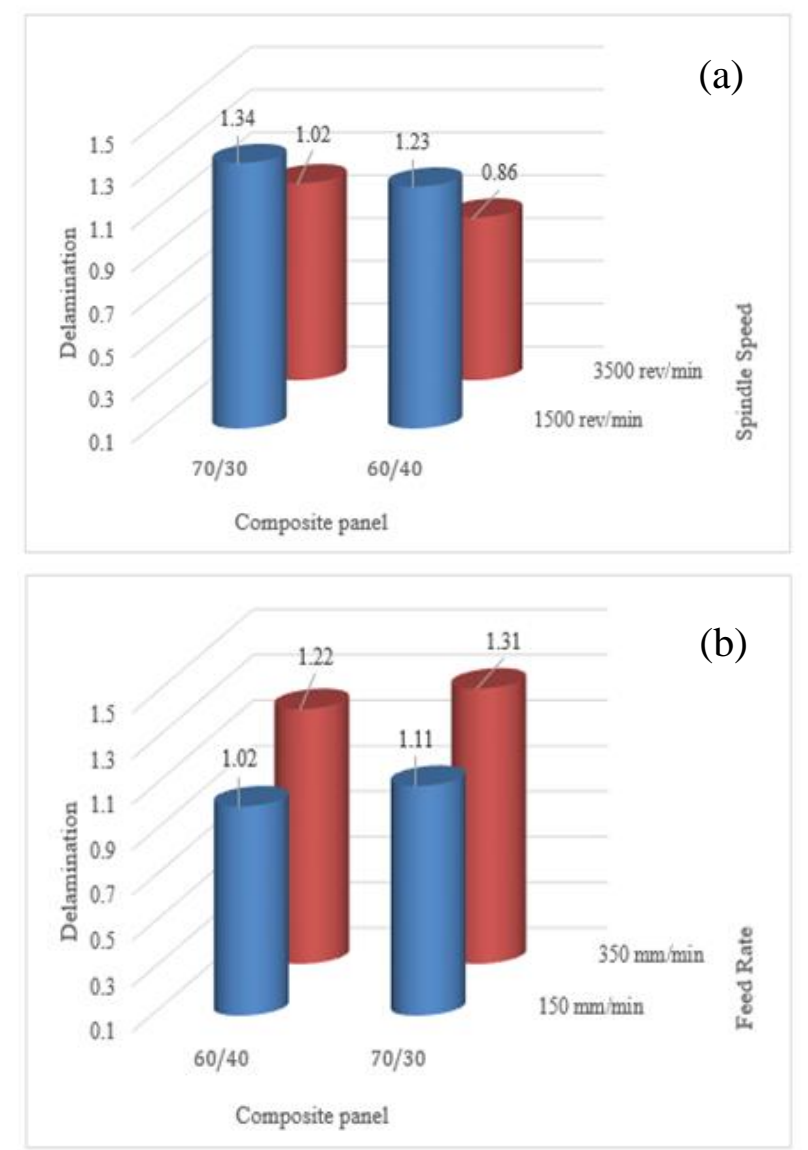

Figure 6 (a) Different spindle speed (3500 rpm \& $1500 \mathrm{rpm}$ ) effect on delamination; (b) different feed rate $(350 \mathrm{~mm} / \mathrm{min}$ and $150 \mathrm{~mm} / \mathrm{min})$ effect on delamination

\section{Tool Wear Analysis for 60/40 panel}

Tool wear is measured in the view of flank wear according to ISO (1989) standard until $0.3 \mathrm{~mm}$. In this machining also followed the machining until the carbide cutting tool reaches the ultimate flank wear. It can be seen from the figure 7 that different spindle speed (671.57 rev/min to $6328.43 \mathrm{rev} / \mathrm{min})$, feed rate $(108.58 \mathrm{~mm} / \mathrm{min}$ to $391.42 \mathrm{~mm} / \mathrm{min})$ and depth of cut $(0.79 \mathrm{~mm}$ to $2.21 \mathrm{~mm})$ is used to find the flank wear of the cutting tool. Figure 7 (a) exhibits that whenever the spindle is higher (6328.43 rev/min) then the flank wear is very faster and after traveling $9600 \mathrm{~mm}$ distance reaches $0.311 \mathrm{~mm}$ flank wear. Gradually the spindle speed was decreasing from $6328.43 \mathrm{rev} / \mathrm{min}$ to $671.57 \mathrm{rev} / \mathrm{min}$ then the cutting tool traveled a long distance to reach the ultimate flank wear. It can be seen from the figure also that 671.57 rev/min spindle speed takes a long time to reach $0.307 \mathrm{~mm}$ flank wear. It can travel $13600 \mathrm{~mm}$ distance at lower spindle speed. It could happen because the cutting tool creates lower temperatures surrounding the cutting tool due to lower spindle speed [7]. It also can be seen in figure 7 (b) that different feed rate $(108.58 \mathrm{~mm} / \mathrm{min}$ to $391.42 \mathrm{~mm} / \mathrm{min})$ has an effect on tool wear as well. The lower feed rate 109.58 
$\mathrm{mm} / \mathrm{min}$ takes a longer time to reach at $0.309 \mathrm{~mm}$ flank wear and the distance traveled $10200 \mathrm{~mm}$. On the other hand, the highest feed rate $391.42 \mathrm{~mm} / \mathrm{min}$ traveled shorter distance $(9200 \mathrm{~mm})$ to reach at $0311 \mathrm{~mm}$ flank wear. It can be done because the traversing rate increased with the increase in feed rate and the tool wear become faster [8]. Finally, it can be seen in figure 7 (c) that whenever the depth of cut increased from $0.79 \mathrm{~mm}$ to $2.21 \mathrm{~mm}$ then the flank wears also affected. The depth of cut is higher then the cutting tool has to remove more materials from the surface and tool wear increases. At a lower depth of cut $0.79 \mathrm{~mm}$ shows that the carbide cutting tool can travel more distance comparing to $2.21 \mathrm{~mm}$ and 1.50 $\mathrm{mm}$.
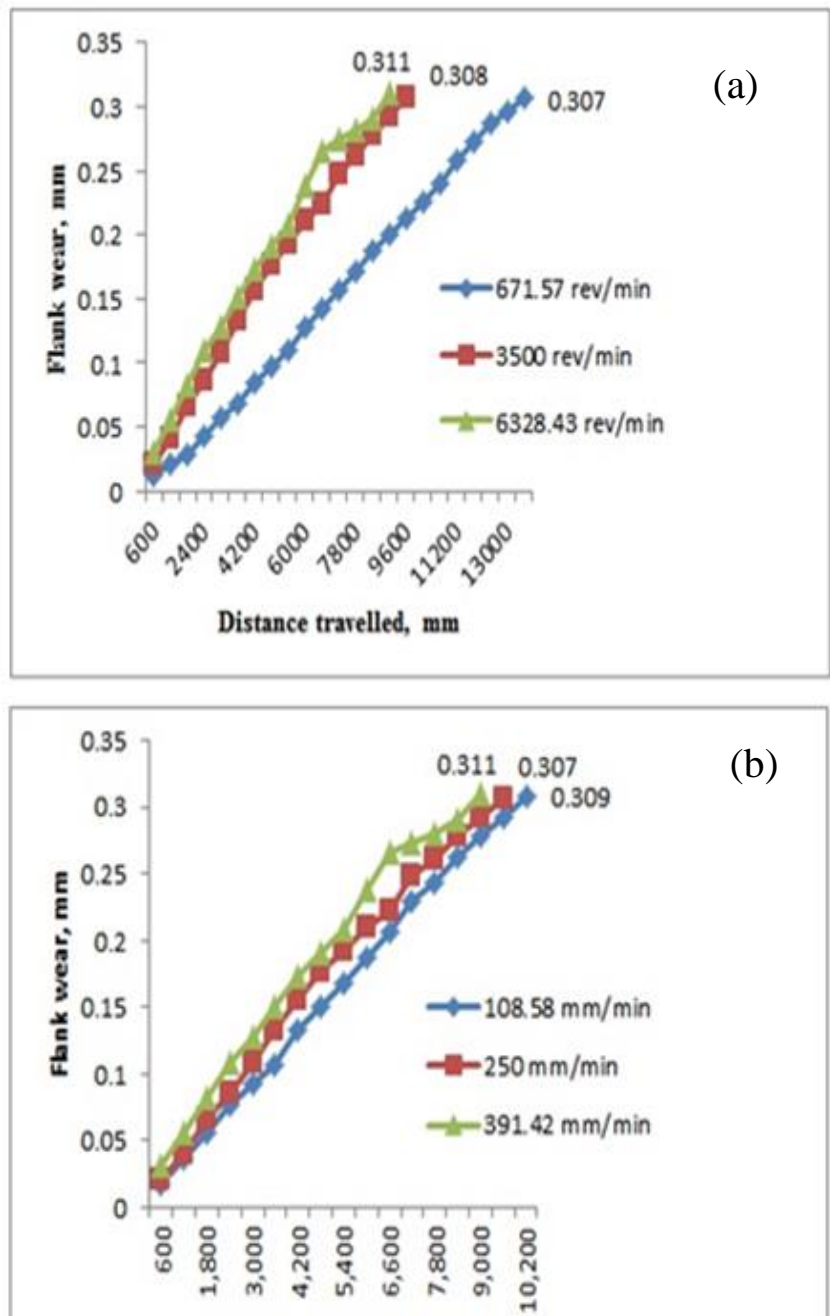

(b)

Distance Travelled, mm

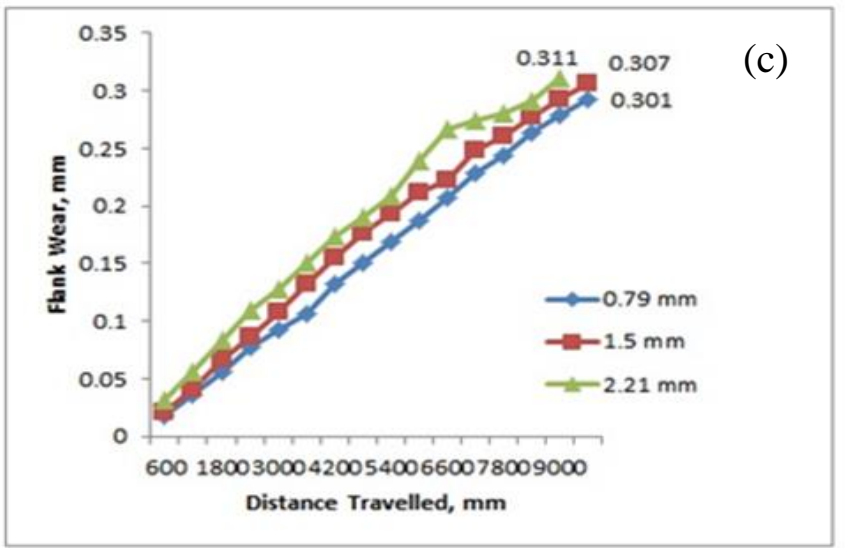

Figure 7 (a) Different spindle speed ( $6328.43,3500 \& 671.57 \mathrm{rev} / \mathrm{min}$ ) effect on tool wear; (b) Different feed rate $(391.42,250 \& 108.58 \mathrm{~mm} / \mathrm{min})$ effect on tool wear; (c) Various Depth of cut (2.21, $1.5 \& 0.79)$ effect on tool wear

\section{Tool life Analysis}

Tool life is one of the major issues to cut the JFRP panel for the better output performance of machining. Figure (8) illustrates that tool life is affected by the changes in spindle speed, feed rate and depth of cut. From the figure 8 (a), it can be seen that whenever spindle speed increases from 671.57 $\mathrm{rev} / \mathrm{min}$ to $6328.43 \mathrm{rev} / \mathrm{min}$ and the feed rate $(250 \mathrm{~mm} / \mathrm{min})$ and depth of cut $(1.50 \mathrm{~mm})$ was constant then the tool life was decreasing from $35.88 \mathrm{~min}$ to $14.4 \mathrm{~min}$. It could happen because the higher spindle speed has an interaction force between the workpiece and tool material [9]. It generates high temperatures between the workpiece material and tool to create faster wear in the carbide cutting tool. Figure 8 (b) reveals that with the increase of feed rate from 108.58 $\mathrm{mm} / \mathrm{min}$ to $391.42 \mathrm{~mm} / \mathrm{min}$ then the tool life also decreased because the friction arises between the workpiece and tool material. It also generates high temperatures and decreases the tool life from $41.6 \mathrm{~min}$ to $13.5 \mathrm{~min}$. Figure 8 (c) shows that, higher the depth of cut and lower the tool life. The depth of cut was increased from $0.79 \mathrm{~mm}$ to $2.21 \mathrm{~mm}$ then tool life also decreased because of the lowest depth of cut have to remove less material comparing to higher depth cut. However, it can be seen that the lowest depth of cut $(0.79$ $\mathrm{mm}$ ) shows the tool life is longer comparing to the highest depth of cut $(2.21 \mathrm{~mm})$.

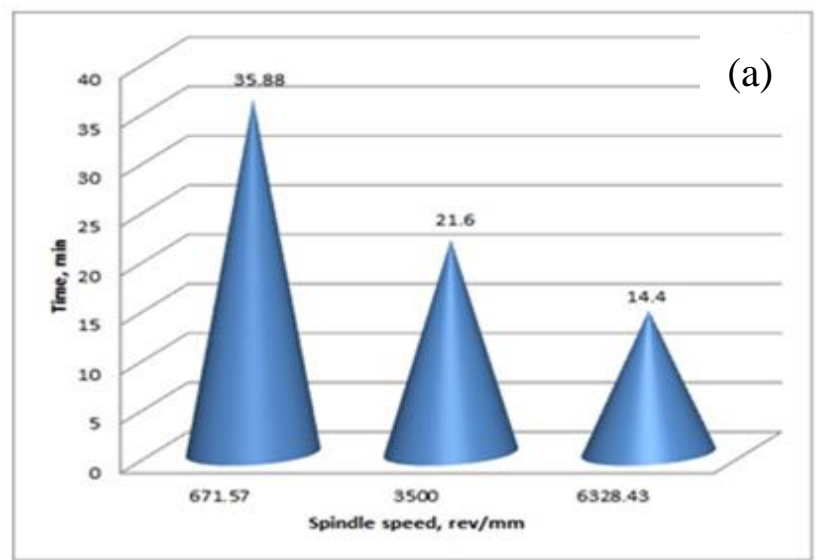



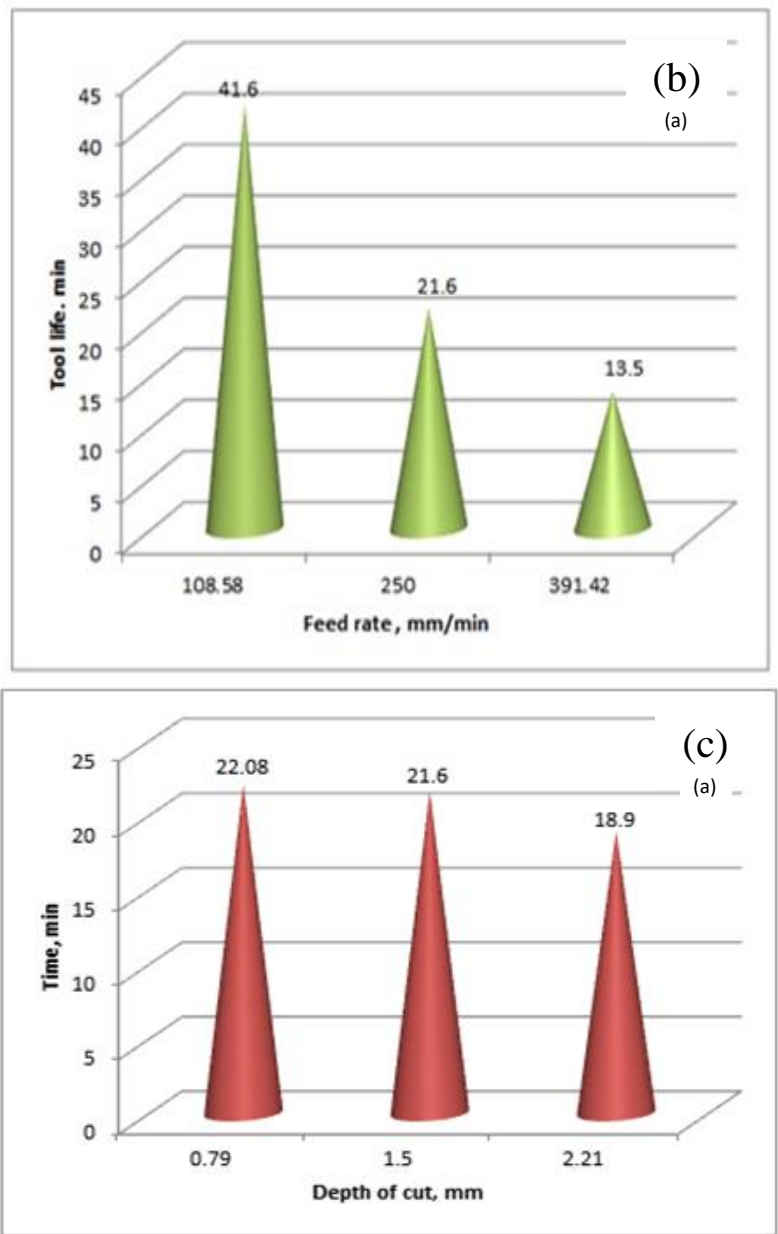

Figure 8 (a) Different spindle speed ( 6328.43, 3500 \& $671.57 \mathrm{rev} / \mathrm{min}$ ) effect on tool life; (b) Different feed rate (391.42, $250 \& 108.58 \mathrm{~mm} / \mathrm{min})$ effect on tool life; (c) Various Depth of cut $(2.21,1.5 \& 0.79)$ effect on tool life

\section{CONCLUSION}

In the investigation of the above study, it was found that a preliminary experiment on different composite panels shows that $60 / 40$ JFRP panel is better than 70/30 panel. The spindle speed and feed rate both have an effect on this composite panel to. Tool wear is higher at 70/30 panel and delamination also comparing to $60 / 40$ panels. The selected $60 / 40$ composite panel was machined according to DOE table. After machining the selected composite panel, it was found that higher spindle speed (6328.43 rev/min), feed rate (391.42 $\mathrm{mm} / \mathrm{min}$ ) depth of cut (2.21) gives the highest flank wear and tool life is decreased. The tool life increased at a lower depth of cut $(0.79 \mathrm{~mm})$. These experimental table gives us the range of machining parameter and also the tool wear and tool life analysis.

\section{ACKNOWLEDGEMENTS}

This research was conducted in Tool and die lab, workshop and metrology lab in International Islamic University Malaysia. Composite lab was used to fabricate the JFRP panel. Author is grateful towards the modern lab facility and help of lab assistant as well.

\section{REFERENCES}

[1] Wang, X., L.J. Wang, and J.P. Tao, Investigation on thrust in vibration drilling of fiber-reinforced plastics.Journal of Materials Processing Technology, 2004. 148(2): p. 239-244.)

[2] Mohan, N.S., A. Ramachandra, and S.M. Kulkarni, Influence of process parameters on cutting force and torque during drilling of glassfiber polyester reinforced composites. Composite Structures, 2005. 71(3-4): p. 407-413.

[3] Dandekar, C.R. and Y.C. Shin, Modeling of machining of composite materials: A review. International Journal of Machine Tools and Manufacture, 2012. 57: p. 102-121.

[4] Lasri, L., M. Nouari, and M. El Mansori, Modelling of chip separation in machining unidirectional FRP composites by stiffness degradation concept. Composites Science and Technology, 2009. 69(5): p. 684-692.

[5] Hocheng, H. and C.C. Tsao, The path towards delamination-free drilling of composite materials. Journal of Materials Processing Technology, 2005.167(2-3): p. 251-264.

[6] Palanikumar, K. and J. Paulo Davim, Mathematical model to predict tool wear on the machining of glass fibre reinforced plastic composites. Materials \& Design, 2007. 28(7): p. 2008-2014.

[7] Paulo Davim, J., P. Reis, and C. Conceição António, Drilling fiberreinforced plastics (FRPs) manufactured by hand lay-up: influence of matrix (Viapal VUP 9731 and ATLAC 382-05). Journal of Materials Processing Technology, 2004. 155-156(0): p. 1828-1833.

[8] Teti, R., Machining of Composite Materials. CIRP Annals Manufacturing Technology, 2002. 51(2): p. 611-634.

[9] Iliescu, D. Gehin, D.Gutierrez, M. E.Girot, F., Modeling and tool wear in drilling of CFRP. International Journal of Machine Tools and Manufacture, 2010. 50(2): p. 204-213. 